\title{
NUTRITIONAL DISTURBANCES ASSOCIATED WITH DISEASES OF THE STOMACH AND DUODENUM*
}

\author{
WALTER G. MADDOCK, M.D. \\ Associate Professor of Surgery, University of Michigan School of Medicine \\ ANN ARBOR, MICHIGAN
}

$\mathrm{T}$ $O$ view surgical lesions of the stomach and duodenum from the standpoint of etiology, symptoms and signs, pathology, and operative correction is to miss much. Altered physiology and biochemistry are also important and the surgeon of today has broadened his field to understand and correct the deficiencies resulting from nutritional disturbances. These deficiencies may be associated with the vitamins, minerals, proteins, carbohydrates and fats, either individually or in combination.

Caloric requirements cannot always be entirely provided for, but even with complete pyloric obstruction, energy for many days is obtained since the body oxidizes its own tissues. The parenteral administration of glucose is a distinct aid in preventing ketosis; actually suffrcient glucose can be given to maintain the glycogen reserves of the body at a fair level. However, the substances that can be administered in quantities by the intravenous channelwater, glucose and sodium chloride-are inadequate by themselves to maintain health for more than two or three weeks. Vitamins and proteins are also needed and these requirements are often a considerable problem for the seriously ill patient. For many of them the period of malnutrition has existed for months before the operation, and a long-standing deficit is present. The purpose of this paper is to review briefly the vitamin and protein deficiencies as they may affect the surgical patient with a lesion of the stomach or duodenum.

\section{VITAMIN DEFICIENCIES}

In 1934 , Strauss ${ }^{1}$ presented an excellent article on the rôle of the gastrointestinal trace in deficiency disease, in which he pointed out that disturbances in digestion and absorption, as by vomiting, diarrhea or dysentery, are in the north temperate regions a more frequent cause of deficiencies than inadequate composition of the diet. McCollum, ${ }^{2}$ in 1937 , summarized the recent advances in nutritional research and Youmans, ${ }^{3}$ at about the same time, stressed the recognition of the mild or early forms of deficiency, which must be much more common in many groups of seriously ill surgical patients than is realized. This subject merits closer attention from the surgeon.

Vitamin A. A case of night blindness due to a nutritional deficiency associated with a gastrocolic fistula was reported by Wilbur and Eusterman ${ }^{4}$ in 1934. The patient had had a gastroenterostomy for a duodenal ulcer in 1919, and in 1929 symptoms of jejunal ulceration appeared. Two years later, in I931, diarrhea from a gastrocolic fistula began, and periods of night blindness occurred. The four to six semi-soft stools daily contained undigested food particles. Following operative closure of the fistulous connection the diarrhea and the night blindness disappeared.

Studies have shown that night blindness, or difficult vision in faint illumination, depends upon a disturbance in the metabolism of visual purple of the retinal rods and that the disturbance is related to a vitamin a deficiency. Milder forms of the deficiency, short of actual night blindness, are rather common; Corlette, Youmans, Frank and Corlettc ${ }^{5}$ recently reported that 50 per cent of a representative group of adult clinic patients in the mid-south 
showed vision below normal standards by the photometer test.

Vitamin A deficiency may also be manifested in a keratinization of epithelial cells in glands and their ducts, and in many organs. Wolbach ${ }^{6}$ presents an excellent discussion of this pathologic change among others resulting from vitamin deficiency. As a test for this keratinization Blackfan and Wolbach ${ }^{7}$ made smears from conjunctival scrapings, which, when stained, showed the abnormal presence of cornified epithelial cells. Skin changes suggested by Frazier and $\mathrm{Hu}^{8}$ as diagnostic, consist of keratotic papules of varying size arising from pilosebaceous follicles, and commonly found over the thighs, arms and shoulders. In two of Youman's ${ }^{3}$ patients these lesions cleared up after treatment with cod liver oil.

Fish oils contain large amounts of vitamin $\mathrm{A}$ and are therefore commonly used for treating this deficiency. Carotene, ${ }^{1}$ a precursor of vitamin $\mathrm{A}$, can be given as a rich source of the vitamin. The oils are less expensive, however, and have other vitamins present.

Vitamin $B_{1}$. The most common cause of peripheral polyneuritis in this country is the dietary deficiency associated with chronic alcoholism. Lettsom ${ }^{9}$ first described alcoholic polyneuritis in 1787 and for decades thereafter the disease was thought to be a direct effect of alcohol. In I928, Shattuck ${ }^{10}$ suggested that the poor diet of the chronic alcoholic was the cause of the disturbance, and subsequent studies have corroborated this opinion. Evidence now is even more specific, the disease being considered as due to a deficiency of vitamin $\mathbf{B}_{\mathbf{1}}$.

In a few cases, surgical lesions of the gastrointestinal tract have been responsible for peripheral polyneuritis. The disorder has been secondary to pyloric stenosis associated with peptic ulcer and gastric carcinoma and polyps, and also secondary to gastroenterostomy and to persistent vomiting following biliary tract operations. That the failure of the gastrointestinal tract to retain food can result in this deficiency is further shown by the occurrence of peripheral polyneuritis in case of "pernicious vomiting" of pregnancy. ${ }^{1}$

Mild or subclinical forms of vitamin $B_{1}$ defrciency are undoubtedly widespread, but are very difficult to diagnose. Many people so afflicted drag about with anorexia, vague pains, weakness, indigestion and hypotonicity of the bowel. A calculation of the vitamin $B_{1}$ inadequacy of the diet by Cowgill's formula ${ }^{11}$ promises to be very helpful. ${ }^{12}$ Trial by treatment is also worthwhile when deficiency is suspected.

In the treatment of mild forms of vitamin $B_{1}$ deficiency or of actual multiple polyneuritis, yeast or yeast concentrates are commonly used. ${ }^{2}$ A pure crystalline form of vitamin $B_{1}$ is now available and can be given parenterally. Vorhaus, Williams and Waterman ${ }^{13}$ reported excellent results with this substance in over 100 cascs of deficiency. Weiss and Wilkins ${ }^{14}$ more recently used the crystalline preparation, among other substances, in the treatment of cardiovascular disturbances associated with vitamin $\mathbf{B}_{1}$ deficiency and obtained remarkable improvements.

Vitamin $B_{2}$. Pellagra, as commonly seen in its endemic form, is due to a deficiency of vitamin $\mathrm{B}_{2}$. The sporadic cases in the northern part of the country are almost always associated with organic diseases of the gastrointestinal tract or with chronic alcoholism. ${ }^{1}$ Eusterman and Balfour ${ }^{15}$ found pellagra to be the most common vitamin deficiency encountered in disorders of the stomach and duodenum. Actual primary lesions reported as causes of pellagra ${ }^{1}$ are: pyloric obstruction from gastric carcinoma or peptic ulcer; unnecessary gastroenterostomy; gastric syphilis; esophageal stricture; jejunostomy feedings; ulcerative colitis; amebic dysentery; jejunal stenosis; ileac stenosis; and rectal stricture. As mentioned previously, besides the importance of inadequate intake of food, other factors, such as failure to retain the food through obstruction or diarrhea, and failure properly to assimilate 
the food, also play a significant part in producing the deficiency.

In the recognition of pellagra associated with gastrointestinal disease, the cutaneous changes on the exposed parts of the body, the hands, wrists, and face are most important. ${ }^{15}$ The common lesions may vary from a hyperkeratosis and blotchy pigmentation to extensive bullous lesions. With chronicity the skin becomes hardened, rough, scaly and permanently pigmented. The distribution on the wrists and forearms has repeatedly earned the phrase "gauntlet" or "glove" dermatitis. Usually the lesions associated with gastrointestinal disorders are less severe than those observed in pellagrous regions, and hyperkeratoses with a dryness and scaliness of the skin suggests a mild defrciency. The tongue, which in severe disturbances is red, swollen, dry and ulcerated, in mild cases is merely reddened and smooth along the sides and tip. Field ${ }^{16}$ has found the skin and tongue signs of mild deficiency to be quite common among hospital patients in Ann Arbor. The constant presence of diarrhea in the severe cases is often absent or replaced by constipation in the milder forms. Commonly associated with dermatitis and diarrhea in severe pellagra, is dementia. This usually is in the form of a delirium similar to that seen in other infectious or toxic states.

The treatment of secondary pellagra is inseparably connected with the treatment of the primary gastrointestinal disease. Pre-operative dietary measures should be carried out if at all possible. In many cases the operation, as, for example, the relief of pyloric obstruction, has to come first. Later, the addition of proper foods should be started as soon as possible; yeast, eggs, milk, the juices of citrous fruits, cod liver oil, lean meat and green vegetables are particularly essential. Yeast or yeast concentrates require special emphasis because they apparently contain all of the "B-factors" and can be given when patients are taking only fluids. Liver extracts have been shown to be of value in pellagra, but it is rather unfortunate that present day parenteral preparations for pernicious anemia have been so purified that possible vitamin $\mathbf{B}_{2}$ elements have been largely eliminated. Within recent months nicotinic acid has been employed and has shown promising results in the treatment of pellagrins. ${ }^{17}$

Vitamin C. Interest in vitamin $\mathrm{C}$ is now largely concerned with the recognition of early signs of the deficiency, since typical scurvy is quite rare. The pure vitamin substance, known as ascorbic or cevitamic acid, has been synthesized by several procedures and is relatively inexpensive.

Many observers believe that mild or latent scurvy is quite common. Yavorsky and King ${ }^{18}$ estimate that at post mortem 20 per cent of the subjects show mild deficiency. Youmans, Corlette, Akeroyd and Frank ${ }^{19}$ found latent scurvy in twelve of fifteen adults whose diets were suspected of being inadequate in vitamin c. For the better detection of mild deficiency, methods have been developed for the determination of (I) the urinary excretion, ${ }^{20}$ (2) the body store, ${ }^{20}$ and (3) the blood plasma or serum concentration of cevitamic acid. ${ }^{21,22} \mathrm{~A}$ further promising test ${ }^{23}$ consists in the production of venous stasis in an arm for fifteen minutes with a blood pressure cuff at $50 \mathrm{~mm}$. of mercury and then the counting of the number of petechial hemorrhages in a skin area of $60 \mathrm{~mm}$. in diameter in the antecubital fossa. A positive test consists in the presence of more than eight petechiae; five or fewer constitute a negative reaction.

With the problem of hemorrhage in surgical patients it is odd that little mention is made of vitamin $c$. The tests developed and the availability of cevitamic acid should lead to studies in this regard.

Vitamin D. The association of vitamin D with rickets is well known. Further studies connected it with the development of the teeth and with osteoporosis, osteomalacia, tetany and some forms of pathologic fractures. Definite deficiencies in vitamin $\mathrm{D}$ have been secondary to gastro- 
intestinal diseases ${ }^{1,3}$ in which the absorption of food has been interfered with, such as in celiac disease, sprue, external biliary fistula and chronic jaundice. Excellent reports by Ivy, Shapiro and Melnick, ${ }^{24}$ McNealy, Shapiro and Melnick, ${ }^{25}$ and Boys $^{26}$ are available to show the value of viosterol in lessening the hemorrhagic tendency in patients with jaundice.

Anemia. Anemia is not known to be due to a vitamin deficiency, but is frequently associated with nutritional disturbances. The blood picture secondary to diseases of the gastrointestinal tract ${ }^{27}$ varies considerably in type and extent. In the absence of gross bleeding, patients with gastric or duodenal ulcers usually show little change from the normal. On the other hand, patients with gastric carcinoma generally show a secondary anemia as a result of a continual oozing of blood from the carcinomatous surface. The degree of anemia found in such cases has been reported as roughly proportional to the extent of the lesion. ${ }^{28}$

Achlorhydria is a common finding in both gastric carcinoma and pernicious anemia. Although not with the frequency one might expect, these two diseases have been coexistent. Conner and Birkeland ${ }^{29}$ reviewed twenty such cases, and in most instances found the onset of the gastric carcinoma and the pernicious anemia to be approximately simultaneous.

Pernicious anemia has followed partial gastrectomy for carcinoma, ulcer and syphilis of the stomach, and also gastroenterostomy for peptic ulcer. Goldhamer ${ }^{30}$ summarized the findings in twenty-three such cases and pointed out that a number of years generally passed before the pernicious anemia became apparent.

The treatment to be carried out for the anemias depends largely upon the type. The secondary anemias of hemorrhage respond well to large doses of iron; iron and ammonium citrate, reduced iron and ferrous sulphate are quite satisfactory. For pernicious and other forms of hyperchromatic anemia, liver therapy is indicated.

\section{PROTEIN DEFICIENCY}

Among surgical patients with malnutrition from serious disturbances of gastrointestinal function, the effects of protein deficiency are more frequently seen than are those of vitamin deficiencies. Prolonged low protein ingestions result in low plasma proteins, and "nutritional edema" as rather common sequelae. Jones and Eaton, ${ }^{31}$ in 1933, presented a series of thirty-four patients who showed edema following operations, mainly operations on the gastrointestinal tract. The majority of the patients were undernourished prior to operation because of malignancy, pyloric obstruction and similar conditions. Most of them had serum proteins below the critical level of Moore and Van Slyke ${ }^{32}$ at which edema tends to develop (a total serum protein of $5.5 \pm 0.3 \mathrm{Gm}$. per 100 c.c.; serum albumin $2.5 \pm 0.2 \mathrm{Gm}$. per Ioo c.c.).

Besides the low serum protein, Jones and Eaton ${ }^{31}$ considered profuse surgical drainage, the general effects of sepsis, loss of serum protein by massive hemorrhage, a retention of base due to temporary disturbance of renal function, and the administration of excessive amounts of water and salt as additional factors in the production of edema. The latter is of particular importance, since seriously ill patients presenting malnutrition or sepsis were shown by Coller, Dick and Maddock ${ }^{33}$ routinely to develop water retention if water requirements were supplied intravenously in the form of saline solutions and sodium chloride was not needed. This occurred, as suggested also by Jones and Eaton, even when the serum protein level was approximately normal. While all the factors mentioned set the stage for the development of edema in surgical patients, in the experience of Coller, Dick and Maddock the administration of unnecessary amounts of saline solution to patients with malnutrition or sepsis was almost invariably the common agent precipitating the edema. From an experimental study on dogs involving low serum proteins 
Weech, Snelling and Goettsch ${ }^{34}$ agree with other investigators that salt is essential for edema. In a recent publication Curphey and $\mathrm{Orr}^{35}$ stress the relationship of low serum protein and cxcess sodium chloride to edema. The first thought of the surgeon on finding edema in a sick surgical patient who has been receiving fluids parenterally should therefore be: "What are the serum protein values and how much sodium chloride has been given?"

Studies have shown that the sodium radical rather than the chlorine ion is the important factor in water retention, ${ }^{36}$ and sodium is therefore to be avoided. Nevertheless, water has to be given parenterally to many surgical patients to provide for urine output and vaporization from the skin and lungs. If administered intravenously as 5 per cent dextrose in distilled water, it rarely produces edema. ${ }^{33}$ It is unnecessary and even harmful to the sick patient to administer more than a few grams of sodium chloride daily when the plasma chlorides and the carbon dioxide combining power are normal and no abnormal loss of sodium chloride is occurring. The only reason that retention of water is not more evident when saline solutions are used routinely without thought as to whether or not sodium chloride is needed is that the administration is generally for a day or two only. With saline administrations for several days edema would certainly appear.

In the majority of cases the damage done by edema fluid is not clearly apparent, but in others the harmful effects are quite striking. Five of the patients reported by Jones and Eaton developed edema of the lungs and in several others impairment of function of a gastroenterostomy was thought to be due to edema of the gastrointestinal wall. Ravdin and his associates $^{37,38}$ have shown this latter possibility to be a fact. In an excellent piece of experimental work on dogs, the gastric emptying time was found to increase as the serum proteins were decreased. This occurred whether the stomach was intact or had a gastroenterostomy. At post-mortem the gastric stoma of the latter dogs showed a marked reduction in size because of edema.

The significance of these important findings should be apparent to all surgeons. As Kirklin ${ }^{39}$ and Barden, Ravdin and Frazier $^{40}$ have pointed out, roentgenologic findings showing gastric retention after operations should be cautiously interpreted as evidence of mechanical obstruction at the site of the anastomosis. Experience has shown that in time the difficulties in some cases straighten out. Ravdin's ${ }^{37}$ observations lead him to believe that the frequently fatal operation for the relief of the alleged obstruction can be generally avoided if the patient is aided by repeated blood transfusions and proper feedings through a jejunostomy. Curphey and Orr also advocate repeated blood transfusions when edema appears in cases of prolonged and serious illness.

As a prophylactic measure in his patients with long-standing, severe malnutrition Ravdin advises several transfusions prior to the operation and also the passage of a Jutte tube down through the gastroenterostomy stoma to the distal jejunum at the time of the operation. Proper nourishment can then be given early in the post-operative period. Eggs and milk are a good source of readily available protein. Yeast concentrate and cod liver oil can also be given through the tube. As solid foods are tolerated, the lean meats, salmon, liver, eggs, milk and cream, the juices of citrous fruits, spinach, lettuce, asparagus, fresh peas, cabbage and tomatoes should be fed. When the patient can ingest these substances, concern about vitamin and protein defrciencies is well past.

In the care of the seriously ill patient, whose relief from disease gives the greatest satisfaction to the physician, the best results are obtained from treatment based on a broad knowledge of every alteration from the normal. 


\section{REFERENCES}

I. Strauss, M. B. The role of the gastro-intestinal tract in conditioning deficiency disease. $J$. A. M. A., I03: 1, 1934.

2. McCollum, E. V. Recent advances in nutritional research. Micbigan State $M . J ., 36: 211$, 1937.

3. Youmans, J. B. The present status of vitamin deficiencies in practice. J.A.M.A., $108:$ is, 1937.

4. Wilbur, D. L., and Eusterman, G. B. Nutritional night blindness: report of a case. J. A. M. A., 102: 364, 1934.

5. Corlette, M. B., Youmans, J. B., Frank, H., and Corlette, M. G. Photometric studies of visual adaptation in relation to mild vitamin A deficiency in adults. Am. J. M. Sc., 195: 54, 1938.

6. Wolbach, S. B. The pathologic changes resulting from vitamin deficiency. J. A.M.A., 108: 7, 1937.

7. Blackfan, K. A., and Wolbach, S. B. Vitamin a deficiency in infants. J. Pediat., 3: 679, 1933.

8. Frazier, C. N., and $\mathrm{Hu}, \mathrm{C}$. K. Cutaneous lesions associated with deficiency in vitamin $\mathrm{A}$ in man. Arch. Int. Med., 48: $507,1931$.

o. Letrsom, J. C. Some remarks on the effects of lignum quassiae amarae. Mem. Med. Soc. London, I : 1 28, 1779-1787.

10. Shattuck, G. C. Relation of beriberi to polyneuritis from other causes. Am. J. Trop. Med., 8: 539,1928 .

I I. Cowglll, $G$. $R$. The vitamin requirements of man. J. Am. Diet. A., 13: 195, 1937.

i 2. Jolliffe, N. H., Colbert, C. N. and Joffe, P. M. Observations on the etiologic relationship of vitamin $\mathbf{B}\left(\mathbf{B}_{1}\right)$ to polyneuritis in the alcoholic addict. Am. J. M. Sc., 191: 515, 1936.

13. Vorhaus, M. G., Williams, R. R., and WaterMAN, B. S. Studies on crystalline vitamin $B_{1}$ : experimental and clinical observations. $J . A$. M. A., 105: $1580,1935$.

1.4. Weiss, Soma, and Wilkins, R. W. The nature of the cardiovascular disturbances in nutritional deficiency states. Ann. Int. Med., I I: I04, 1937.

i 5. Eusterman, G. B. and Balfour, D. C. The Stomach and Duodenum. Phila., 1936. W. B. Saunders.

16. Field, Henry, Jr. Personal communication to the author.

17. Editorial. Pellagra and nicotinic acid. J. A. M. A., $110: 289$; $193^{8}$.

18. Yavorsky, M., Almaden, P., and King, C. G. Vitamin $\mathrm{C}$ content of human tissues. J. Biol. Cbem., 106: 525, 1934.

19. Youmans, J. B., Corlette, M. B., Akeroyd, J. H., and Frank, H. Studies of vitamin C excretion and saturation. Am. J.M. Sc., I9 I: 319, 1936.

20. Harris, L. J., and RAy, S. N. Diagnosis of vitamin c subnutrition by urine analysis. Lancet, I : 7 I, I935.

2i. Mirsky, I. A., Swadesh, S., and Soskin, Samuel. Total ascorbic acid content of human blood. Proc. Soc. Exper. Biol. of Med., 32: 1130 , I935.
22. FArmer, C. J., and ABT, A. F. Ascorbic acid content of blood. Proc. Soc. Exper. Biol. \& Med., 32: 1625 , 1935.

23. Görhlin, G. F. Outline of a method for the determination of the strength of the skin capillaries and the indirect estimation of the individual vitamin c standard. J. Lab. es Clin. Med., 18: 484 , 1933 .

24. Ivy, A. C., Shapiro, P. F., and Melnick, P. The bleeding tendency in jaundice. Surg., Gynec. ${ }^{\circ}$ Obst., 6o: $78 \mathrm{I}, 1935$.

25. McNealy, R. W., Shapiro, P. F., and Melnick, P. The effect of viosterol in jaundice. Surg., Gynec. es Obst., 60: 785, 1935 .

26. Boys, Floyd. A report on the value of the ivy blceding timc test and the usc of viosterol in cases of obstructive jaundice. Surgery, 2: 817, 1937.

27. Hartman, H. R. in Eusterman, G. B. and BatFour, D. C. The Stomach and Duodenum. ${ }^{15}$

28. Eusterman, G. B., and Bueerman, W. H. Carcinoma of the stomach; present status of diagnosis and prognosis. J. A. M. A., 88: 295, 1927.

29. Conner, H. M., and Birkeland, I. W. Coexistence of pernicious anemia and lesions of the gastrointestinal tract. I. Carcinoma of the stomach. Ann. Int. Med., 7: 89, 1933.

3o. Goldhamer, S. M. The pernicious anaemia syndrome in gastrectomized patients. Surg., Gynec. or Obst., 57: 257, 1933.

31. Jones, C. M., and EAton, F. B. Postoperative nutritional edema. Arcb. Surg., 27: 1 59, 1933.

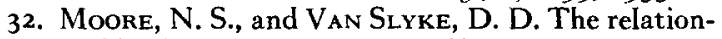
ship between plasma specific gravity, plasma protein content and edema in nephritis. J. Clin. Investigation, 8: 337, 1930.

33. Coller, F. A., Dick, V. S., and Maddock, W. G. The maintenance of normal water exchange with intravenous fluids. J. A. M. A., 107: 1522, $193^{6}$.

34. Weech, A. A., Snelling, C. E., and Goettsch, E. The relation between plasma protein content, plasma specific gravity and edema in dogs maintained on a protein inadequate diet and in dogs rendered edematous by plasmaphoresis. J. Clin. Investigation, 1 2: 193, 1933.

35. Curphey, W. C., and Orr, F. G. Edema in surgical patients. Surgery, I: 589 , 1936.

36. Shelburne, S. A., and Egloff, W. C. Experimental edema. Arch. Int. Med., 48: 51, 193 I.

37. Ravdin, I. S., and Rhoads, J. E. Certain problems illustrating the importance of a knowledge of biochemistry by the surgeon. Surg. Clin. Nortb America, I5: 85, 1935.

38. Mecray, P. M., Barden, R. P., and Ravdin, I. S. Nutritional edema: its effect on the gastric emptying time before and after gastric operations. Surgery, 1 : 53, 1937.

39. KirkliN, B. R. Roentgenologic determination of normal and abnormal results following operation on stomach and duodenum. Am. J. Roentgenol., 33: 468, 1935.

40. Barden, R. P., Ravdin, I. S., and Frazier, W. D. Hypoproteinemia as a factor in the retardation of gastric emptying time after operations of the Billroth 1 or il types. Am. J. Roentgenol., 38: 196, 1937. 